\title{
Heredia, introductor del romanticismo
}

osé María Heredia (1803-1839), como se nota muy claramente por su poema "En el Teocalli de Cholula", no sólo fué quien introdujo en México el romanticismo europeo, sino también uno de los primeros poetas románticos, en lengua española. Desterrado de Cuba, Heredia, antes de vivir en México, estudió en otras ciudades del continente y viajó por él. Al examinar ese poema, vamos a señalar los puntos de contacto que hay entre los románticos europeos y el poeta cubano, así como el valor de éste.

Una de las características sobresalientes del romanticismo, es el hecho de buscar refugio en la naturaleza, que toma dos formas. La primera podemos'llamarla personal, y se encuentra cada vez más fuerte, en Rousseau, Wordsworth, Lamartine y Byron. La segunda forma de "vtuelta a la naturaleza" se manifiesta en la búsqueda de paisajes exóticos. Sus representantes son Bernardin de Saint Pierre y Chateaubriand.

Heredia, gran devoto del autor de Atala, principia su poema con un canto a la naturaleza mexicana. Es una de las primeras ocasiones en que se pinta un paisaje hispanoamericano, en la poesía. Heredia, en un orden muy lógico, comienza por mencionar los productos de la tierra caliente: el naranjo, la piña y el plátano; luego, a medida que sube en altura, crece la grandeza de la manifestación de la naturaleza. Subiendo, pasamos por "la frondosa vid" y el "pino agreste". Al llegar a la cima, el poeta nos premia con una hermosa vista de los majestuosos volcanes: "Iztaccihual purísimo, Orizaba y Popocatepec."

¿Quién, habiendo contemplado los volcanes en un atardecer, no puede sentir la hermosura de la combinación del blanco y el oro, expresada en los versos siguientes de Heredia?: 
... mientras el ancho sol su disco htundía detrás de Iztaccihual. La nieve eterna cual disuelta en mar de oro, semejaba temblar en torno de él; un arco inmenso que del empíreo en el cenit finaba, como espléndido pórtico del cielo, de luz vestido y centelleante gloria, de sus últimos rayos recibía

los colores riquísimos. Su brillo desfalleciendo fué;...

Es propio del poeta romántico escoger la hora de la puesta del sol como la más adecuada para la contemplación de la naturaleza. En el poeta, casi siempre se unen el estado de la naturaleza y la serenidad del crepúsculo, que ayuda a tranquilizar su alma tempestuosa. Siguiendo la tradición de Roberto Burns y Víctor Hugo, exclama Heredia:

¡Crepúsculo feliz! Hora más bella que la alma noche o el brillante día. ¡Cuánto es dulce tu paz al alma mía!

Sin embargo, hay que advertir que aquellos dos poetas europeos se distinguen de Heredia, en este aspecto, en que pintan la visión del crepúsculo con el regreso del campesino a su choza, después de una fatigosa jornada en los campos, mientras que "En el Teocalli de Cholula" presenta un paisaje que sirve para evocar cuadros históricos.

Antes de pasar a la descripción nocturna de los volcanes, Heredia intercala una exclamación que sirve de descanso entre las dos descripciones, y también de insinuación de lo que va a seguir:

... iOh! ¿quién diría

que en estos bellos campos reina alzada

la bárbara opresión, y que esta tierra

brota mieses tan ricas, abonada

con sangre de hombres, en que fué inundada

por la superstición y por la guerra?

Aquí y más adelante, en el poema, Heredia está enseñando a los mexicanos a apreciar la riqueza de temas románticos que se encuentran en su propia historia. También está aludiendo a las luchas por la Independencia que ensangrentaban a todo México. Es interesante notar que Heredia va más allá de su ídolo Chateaubriand; éste 
y toda una hueste de precursores e imitadores se interesaron por el indígena y crearon la leyenda del "noble salvaje". En el poema de Heredia, ya no se halla el puro ennoblecimiento del indio, sino una gran simpatía por los oprimidos y las víctimas del Imperio Azteca. Así es que se descubre en Heredia uno de los temas más favoritos de los románticos: la compasión por los oprimidos de todas las épocas y de todos los países.

En la luz de la luna, y aún más en la completa oscuridad de la noche, el volcán Popocatépetl va creciendo en estatura. Empleando todo su talento poético, Heredia logra que el volcán se nos imponga, como lo más fuerte y más grande del mundo; sobre todo, por el uso de palabras como "colosal", "grandeza", "universal", "stublime" e "inmensos":
Al paso que la luna declinaba, y al ocaso fulgente descendía con lentitud, la sombra se extendía del Popocatepec, y semejaba fantasma colosal. El arco oscuro a mí llegó, cubrióme, y su grandeza fué mayor y mayor, hasta que al cabo en sombra universal veló la tierra. Volví los ojos al volcán sublime, que velado en vapores transparentes, sus inmensos contornos dibujaba de occidente en el cielo.

Después de crear la impresión de la sin par grandiosidad del volcán, Heredia entra propiamente en la materia didáctica del poema. Aquí es donde se nota claramente un punto de contacto con los románticos europeos. E1 volcán de Heredia desempeña el mismo papel que el lago de Lamartine, el sol de Espronceda y el mar de Byron: la fragilidad de las cosas humanas comparadas con la inmortalidad de la naturaleza. Salta a la vista la semejanza entre los trozos siguientes:

Heredia ¡Gigantes del Anáhuac! ¿cómo el vuelo de las edades rápidas no imprime alguna huella en tu nevada frente? Corre el tiempo veloz, arrebatando años y siglos como el norte fiero precipita ante sí la muchedumbre 
de las olas del mar. Pueblos y reyes viste hervir a tus pies, que combatían cual hora combatimos y llamaban eternas sus ciudades, y creían fatigar a la tierra con su gloria.

Fueron: de ellos no resta ni memoria.

Lamartine Ainsi toujours poussés vers de nouveaux rivages, Dans la nuit éternelle emportés sans retour, Ne pourrons-nous jamais sur l'océan des âges, Jeter lancre un seul jour?

$$
\text { ("Le Lac") }
$$

Espronceda ¡Cuántos siglos sin fin cuántos has visto En su abismo insondable desplomarse! ¡Cuánta pompa, grandeza y poderío De imperios populosos disiparse!

$$
\text { ("Himno al Sol") }
$$

Byron Thy shores are empires, changed in all save theeAssyria, Greece, Rome, Carthage, what are they? $T y$ waters washed them power while they were free, And many a tyrant since; their shores obey The stranger, slave, or savage; their decay Has dried up realms to deserts - not so thou;Unchangeable, save to thy wild waves' play, Time writes no wrinkle on thine azure brow:

Such as creation's dawn beheld, thou rollest now.

("Childe Harold")

Heredia sigue el mismo pensamiento, y llega a una conclusión lógica: si todo lo humano es tan frágil, ¿ por qué debemos creer que el volcán sea inmortal? En esto se ve una estrecha relación entre el poeta cubano y Espronceda. Parece que el desterrado español había leído el poema del désterrado cubano:

¿Y tú eterno serás? Tal vez un día de tus profundas bases desquiciado caerás; abrumará tu gran ruina al yermo Anáhuac; alzaránse en ella nuevas generaciones, y orgullosas que fuiste, negarán...

("En el Teocalli de Cholula") 
¿Quién sabe si tal vez pobre destello

Eres tú de otro sol que otro universo

Mayor que el nuestro un día

con doble resplandor esclarecía!

Entonces morirá; noche sombría

Cubrirá eterna la celeste cumbre:

$\mathrm{Ni}$ aun quedará reliquia de tu lumbre!

("Himno al Sol")

Entonces, si ni el volcán ni el sol son inmortales, ¿qué es el mundo sino una serie de cambios irrevocables y la representación de la inestabilidad? Compárense los versos siguientes de Heredia, Espronceda, Shelley y Jorge Manrique:

Heredia ... Todo perece

por ley universal. Aun este mundo

tan bello y tan brillante que habitamos,

es el cadáver pálido y deforme

de otro mundo que fué...

Espronceda ¿Qué hay que la edad con su rigor no altere?

¿no ves que todo es humo, y polvo, y viento?

("E1 Diablo Mundo")

Shelley Naught may endure but mutability.

("Mutability", 1815-1816)

Manrique Pues si vemos lo presente

Como en un punto s'es ydo e acabado,

Si juzgamos sabiamente,

Daremos lo no venido por passado.

No se engañe nadie, no,

Pensando que a de durar lo que espera

Más que duró lo que vió

Pues que todo a de passar por tal manera.

("Coplas a la muerte de su padre")

Nos inquieta un poco ver la misma idea en un poeta del siglo $\mathrm{xv}$ $y$ en varios poetas del siglo diecinueve; pero se puede hacer una distinción muy importante. Es que la mutabilidad del universo pesa a los románticos y aun les espanta; en cambio, Manrique la acepta, y aunque le duele la muerte de su padre, su poema exhala un espíritu de optimismo melancólico. En lugar opuesto a los románticos, el al- 
ma de Manrique se tranquiliza al aceptar la creencia religiosa de que esta vida no es más que un camino hacia la otra: vida apacible y libre de todas las vicisitudes de la vida temporal:

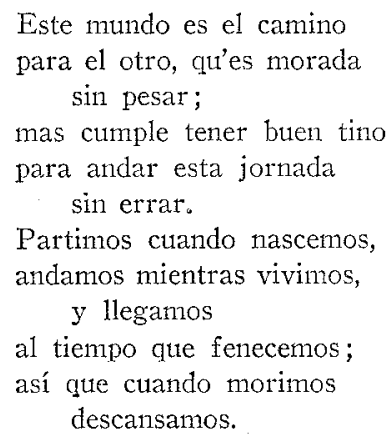

De lo general pasa Heredia a lo particular, hablándonos del caso de los fundadores de Tenochtitlán. El romanticismo del cantor del Niágara ha avanzado más allá del puro interés histórico del novelista Scott. Heredia no se contenta con retratar la historia, sino que siente la necesidad de juzgarla. Por medio de un sueño, evoca toda la pompa de las ceremonias religiosas de los aztecas, con sus cruentos sacrificios humanos, y acaba por reprocharles el haberse creído exentos de la fragilidad humana:

Tales ya fueron

tuts monarcas, Anáhuac, y su orgullo:

su vil superstición y tiranía en el abismo del no ser se hundieron.

Sí, que la muerte, universal señora, hiriendo a par al déspota y esclavo, escribe la igualdad sobre la tumba. Con su mano benéfico el olvido tu insensatez oculta y tus furores a la raza presente y la futura.

No podemos menos que observar la semejanza de estos versos, no sólo con los de Manrique, sino también con los de la famosa "Elegía" del gran precursor del romanticismo inglés, Tomás Gray:

Manrique Esos reyes poderosos que vemos por escripturas ya pasadas, 
con casos tristes, llorosos,

fueron sus buenas venturas trastornadas;

así que no hay cosa fuerte

que a papas y emperadores

e perlados,

así los trata la Muerte

como a los pobres pastores

de ganados.

Gray The boast of heraldry, the pomp of power, And all that beauty, all that wealth e'er gave, Aroaits alike the inevitable hour:

The paths of glory lead but to the grave.

("Elegy in a Country Churchyard")

Para demostrar que este tema ha sido popular a lo largo de todas las épocas de la historia, veámoslo en el gran Cervantes. La muerte, dice,

Con igual pie pisa las altas torres de los reyes como las humildes chozas de los pobres.

(Don Quijote, parte II, capítulo $\mathrm{xx}$ )

No ocupa más pies de tierra el cuerpo del papa que el del sacristán, aunque sea más alto el uno que el otro.

(Don Quijote, parte II, capítulo xxxIII)

Al despertarse Heredia, se desvanece la visión, y el poeta contempla la pirámide de Cholula "muda y desierta". E1 contraste entre el fausto del sueño y las ruinas abandonadas, revela a Heredia la locura del hombre, en su lucha por la gloria:

... y hoy al hombre

que al cielo, cual Titán, truena orgulloso,

sé ejemplo ignominioso

de la demencia y del furor humano.

Me pregunto si Heredia había leído Macbeth, donde dice el inmortal Guillermo Shakespeare que el mundo está:

full of sound and fury and signifying nothing.

Un desarrollo completo de la misma idea se encuentra más tarde en "El Diablo Mundo", de Espronceda: 
Los siglos a los siglos se atropellan; Los hombres a los hombres se suceden En la vejez sus cálculos se estrellan, St pompa y glorias a la muerte ceden : La luz que sus espíritus destellan Muere en la niebla que vencer no pueden, $\mathrm{Y}$ es la historia del hombre y su locura Una estrecha y hedionda sepultura!

En conclusión, podemos decir que José María Heredia fué esencialmente un poeta romántico. A pesar de que todavía siguió, dentro del verso endecasílabo, un orden de palabras ilógico, y empleó alusiones a los dioses clásicos de la antigüedad, contra la forma clásica prevalecieron su vida y sus ideas enteramente románticas.

Es de admirar que hubiera escrito "En el Teocalli de Cholula" en 1820 , o sea antes de que culminara el romanticismo en el continente europeo.

Aunque difiera de los poemas del apogeo del romanticismo europeo, en que no refleja el conflicto personal entre el poeta y la sociedad, esta composición es importantísima, no sólo por haber servido de modelo a los literatos mexicanos, sino también por haber podido servir de inspiración a un poeta español tan insigne como José de Espronceda.

\section{Seymour Menton}

\section{B I B L I O G R A F I A}

Antologia Herediana de José María Heredia y Heredia, preparada por Emilio Valdés y De Latorre, editada por Consejo Corporativo de Educación, Sanidad y Beneficencia. La Habana, 1939.

Carlos González Peña, Historia de la Literatura Mexicana, tercera edición, Editorial Porrúa. México, 1945.

Pedro Henríquez Ureña, Las Corrientes Literarias en la América Hispánica, Biblioteca Americana. México, 1949. 